\title{
Oxidative stress in the trabecular meshwork (Review)
}

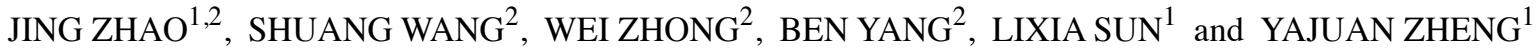 \\ ${ }^{1}$ Department of Ophthalmology, The Second Hospital of Jilin University, Changchun, Jilin 130041; \\ ${ }^{2}$ Department of Ophthalmology, China-Japan Union Hospital, Jilin University, Changchun, Jilin 130031, P.R. China
}

Received February 4, 2016; Accepted August 11, 2016

DOI: $10.3892 /$ ijmm.2016.2714

\begin{abstract}
Glaucoma is the second leading cause of blindness worldwide and elevated intraocular pressure (IOP) is the most important risk factor. High IOP usually occurs as a result of an increase in aqueous humor outflow resistance at the trabecular meshwork (TM). An abnormal TM contributes to the development of glaucoma. Oxidative stress and vascular damage are considered two major cellular factors that lead to alterations in the TM. In this review, we discuss the findings related to oxidative damage to the TM, including the sources of oxidative stress in the TM such as the mitochondria, peroxisomes, endoplasmic reticulum, membrane, cytosol and exogenous factors. We also discuss antioxidants and clinical studies related to protection against oxidative stress in the TM. Although many questions remain unanswered, it is becoming increasingly clear that oxidative stress-induced damage to the TM is related to glaucoma. This may inspire new studies to find better and more stable antioxidants, and better models with which to elucidate the mechanisms involved, and to determine whether in vitro findings translate into in vivo observations. The regulation of the oxidative/redox balance may be the ultimate target for protecting the TM from oxidative stress and preventing glaucoma.
\end{abstract}

\section{Contents}

1. Introduction

2. Oxidative stress

3. Sources of ROS in the TM

4. Oxidative damage in the TM

5. Antioxidants in the TM

6. TM and oxidative stress in vitro/in vivo

7. Clinical studies on protection against oxidative stress for the treatment of glaucoma

8. Conclusion and future perspectives

Correspondence to: Dr Yajuan Zheng, Department of Ophthalmology, The Second Hospital of Jilin University, 218 Ziqiang Street, Changchun, Jilin 130041, P.R. China

E-mail: zhengyajuan124@126.com

Key words: oxidative stress, trabecular meshwork, glaucoma, antioxidants

\section{Introduction}

Glaucoma is the second leading cause of blindness worldwide (1). It is characterized by optic disk changes and progressive visual field loss, and eventually leads to the apoptosis of retinal ganglion cells and axon loss (2). Elevated intraocular pressure (IOP) is the most important risk factor for glaucoma $(3,4)$. High IOP usually occurs as a result of an increase in the aqueous humor outflow resistance of the trabecular meshwork (TM). The TM is composed of trabecular beams made of extracellular matrix (ECM) elements, including fibronectin, laminin and collagen (5). Cells that line the trabecular beams are believed to be essential for regulating the aqueous humor outflow that controls IOP. TM abnormalities are the most common pathogenesis of glaucoma (6-9). Still, the pathogenesis of glaucoma is unclear as is the reason why the TM fails to maintain normal levels of aqueous humor outflow resistance. Oxidative stress and vascular damage (6) are considered two major alterations in the TM related to glaucoma (10). In this review, we discuss findings related to oxidative damage to the TM.

\section{Oxidative stress}

Free radicals are moieties with an unpaired electron and occur as normal metabolites. Under physiological conditions, cells produce up to $10^{11}$ free radicals per day. Free radicals may be classified as oxygen and non-oxygen moieties. Among these, oxygen radicals account for $95 \%$. Oxygen radicals include oxygen and highly reactive oxygenated molecules, such as hydrogen peroxide $\left(\mathrm{H}_{2} \mathrm{O}_{2}\right)$, hydroxyl radical $\left(\mathrm{OH}^{*}\right)$, peroxide hydroxyl radicals, alkoxy radicals, superoxide and the anion radical $\left(\mathrm{O}_{2}^{-}\right)$, which are collectively known as reactive oxygen species (ROS) (11). Reactive nitrogen species also play an important role in oxidative stress (12); however, they will not be discussed in this review.

Under physiological conditions, the production and elimination of ROS are in equilibrium; however, some xenobiotics, ionizing radiation, illnesses, or aging may cause the production of ROS to levels that exceed the neutralizing capacity of an organism, thus leading to a series of pathological changes, which in turn leads to oxidative stress. This process is related to defense mechanisms, such as neutrophil inflammatory infiltrates, an increase in protease secretion and the generation of oxide intermediates. This process is similar to the normal aging process, although more severe (11). It is a prominent feature of many acute and chronic diseases (13). 
Oidative stress plays an important role in pulmonary fibrosis, epilepsy, hypertension, atherosclerosis, Parkinson's disease and sudden death, and it is also known to be associated with a number of ophthalmic diseases, such as age-related macular degeneration, cataract and glaucoma $(14,15)$.

\section{Sources of ROS in the TM}

ROS in cells are derived from both endogenous and exogenous sources. In the endogenous process, the majority of ROS are generated as a by product of normal metabolism (16). The sources of ROS are summarized in Fig. 1.

Mitochondrial ROS production. The mitochondria consume $>90 \%$ of cellular oxygen in aerobic organisms under physiological conditions. Of this, approximately $1-5 \%$ of the oxygen is converted to $\operatorname{ROS}(17,18)$. In the mitochondria, the electron transport chain resides in the inner membrane where electrons are transmitted from NADH/FADH ${ }_{2}$ to oxygen to produce $\mathrm{H}_{2} \mathrm{O}$. However, some electrons leak before they reach the final step, prematurely reacting with $\mathrm{O}_{2}$ to form superoxide instead of $\mathrm{H}_{2} \mathrm{O}(19-21)$.

Peroxisomal ROS production. Peroxisomes are monolayer vesicles, $0.5-1.0 \mu \mathrm{m}$ in diameter, that generally exist in eukaryotic cells. Peroxisomes contain a variety of enzymes, such as flavoenzymes and oxidoreductases. All these enzymes are either involved in the oxidation of fatty acids, D-amino acid catabolism and anabolism, glyoxylate/dicarboxylate metabolism, or in the production of spermidine, an autophagy-stimulating, life-prolonging substance. Peroxisomes produce $\mathrm{H}_{2} \mathrm{O}_{2}$ as a byproduct $(18,22)$ and also produce $\mathrm{O}_{2}^{-}$, which mainly originates from the enzyme, xanthine oxidase, that is also found in the cytosol and is essential for purine degradation (23).

Endoplasmic reticulum ROS production. The mitochondria were believed to be the main producer of ROS in the cell; however, an increasing number of studies over the past decade have indicate dthat the endoplasmic reticulum, as well as peroxisomes produce as much or even more ROS than the mitochondria $(18,22)$. In the endoplasmic reticulum, ROS are mainly produced by cytochrome P450 mono-oxygenases (P450), a superfamily of heme thiol proteins that are also distributed in the mitochondrial inner membrane. P450 is responsible for the synthesis and degradation of endogenous substances (i.e., fatty acids and hormones) and the detoxification of xenobiotics and lipophilic compounds. In this process, electrons are transferred from NADPH to cytochrome P450 via cytochrome $\mathrm{P} 450$ reductase, leading to the hydroxylation of xenobiotics. The leakage of electrons from this system can result in the formation of oxygen radicals, particularly $\mathrm{O}_{2}^{-}(24,25)$.

The endoplasmic reticulum is the main organelle responsible for protein processing. At the early stage of the protein unfolding process, the level of protein disulfide isomerase increases to correct misfolded proteins by forming correct disulfide bonds. Via the folding protein process, protein disulfide isomerase is reduced and an electron is transferred to molecular oxygen and glutathione (GSH). Incomplete transfer leads to the production of superoxide $(26,27)$.
ROS produced in membranes and in the cytosol. Superoxide produced in mitochondrial and plasma membranes (29-31) is due to the activity of NADPH oxidases which is different from all other byproduct process. The superoxide produced in these membranes acts as a signaling molecule to protect against invading microorganisms (28). Electrons are passed on from NADPH to FAD to two b-type hemes and finally to $\mathrm{O}_{2}$, resulting in the formation of superoxide.

In the cytosol, ROS are produced as a byproduct of arachidonic acid metabolism. With NADH or NADPH, superoxide is generated by cyclooxygenase and lipoxygenase enzymes that use arachidonic acid to synthesize prostaglandin $\mathrm{H}_{2}$ or leukotrienes (32). Additionally, in the cytosol, ferrous iron reacts with $\mathrm{H}_{2} \mathrm{O}_{2}$ and, via the Fenton reaction, generates ferric iron, the very reactive hydroxyl radical $\left(\mathrm{OH}^{\circ}\right)$, and hydroxide $\left(\mathrm{OH}^{-}\right)$.

Exogenous factors. Infrared, ultraviolet (UV) and visible light can cause oxidative damage to the eye. UV light induces mutations that have been linked to a variety of ophthalmic pathological changes. UV light can be categorized by its wavelength as: UVA (315-400 nm), UVB (280-315 nm) and UVC (100-280 nm). All UVC and the majority of UVB light are absorbed by the cornea. Only UV wavelengths longer than $295 \mathrm{~nm}$ can be transmitted through the cornea to the anterior chamber; thus the aqueous humor and TM are only exposed to a small amount of UVA. However, even this small amount of UVA leads to the generation of ROS that are one of the main causes of oxidative stress in the TM $(33,34)$. The UV-irradiation process can affect DNA, particularly mitochondrial DNA (mtDNA). It often leads to a 'common' 4977-bp long deletion of mtDNA that can increase mitochondrial ROS production. Increased levels of ROS can also lead to increased levels of mtDNA damage. Infrared light is absorbed by the mitochondrial electron transport chain, particularly at complex IV, leading to an increased leakage of ROS into the mitochondrial matrix. Besides, X-rays, some environmentally toxic moieties and some chemotherapies, as well as inflammation can could cause oxidative damage $(18,35,36)$.

Endogenous and exogenous factors together contribute to pathogenic events that set forth the process of oxidative stressinduced damage. Intense exposure to light, robust metabolic activity, and high oxygen tension are considered the major causes of pathological ROS (37).

The TM is surrounded by aqueous humour and thus the maintenance of the redox state of the aqueous humor is of vital importance to the TM. Inner TM cells resident near the anterior chamber are more severely exposed to oxidative damage $(38,39)$. In the anterior chamber, $\mathrm{H}_{2} \mathrm{O}_{2}$ and other ROS are mainly generated by a light-dependent reaction with iris melanin (40). Metabolic pathways, inflammatory processes and phagocytosis are also important generating pathways. The concentration of $\mathrm{H}_{2} \mathrm{O}_{2}$ in the aqueous humor is believed to be $25 \mu \mathrm{M}(41)$.

\section{Oxidative damage in the $T M$}

Free radicals take part in many important life processes. They are closely related to cell proliferation, differentiation, apoptosis, muscle contraction, nerve conduction and gene expression, and act as second messengers in cell signal trans- 


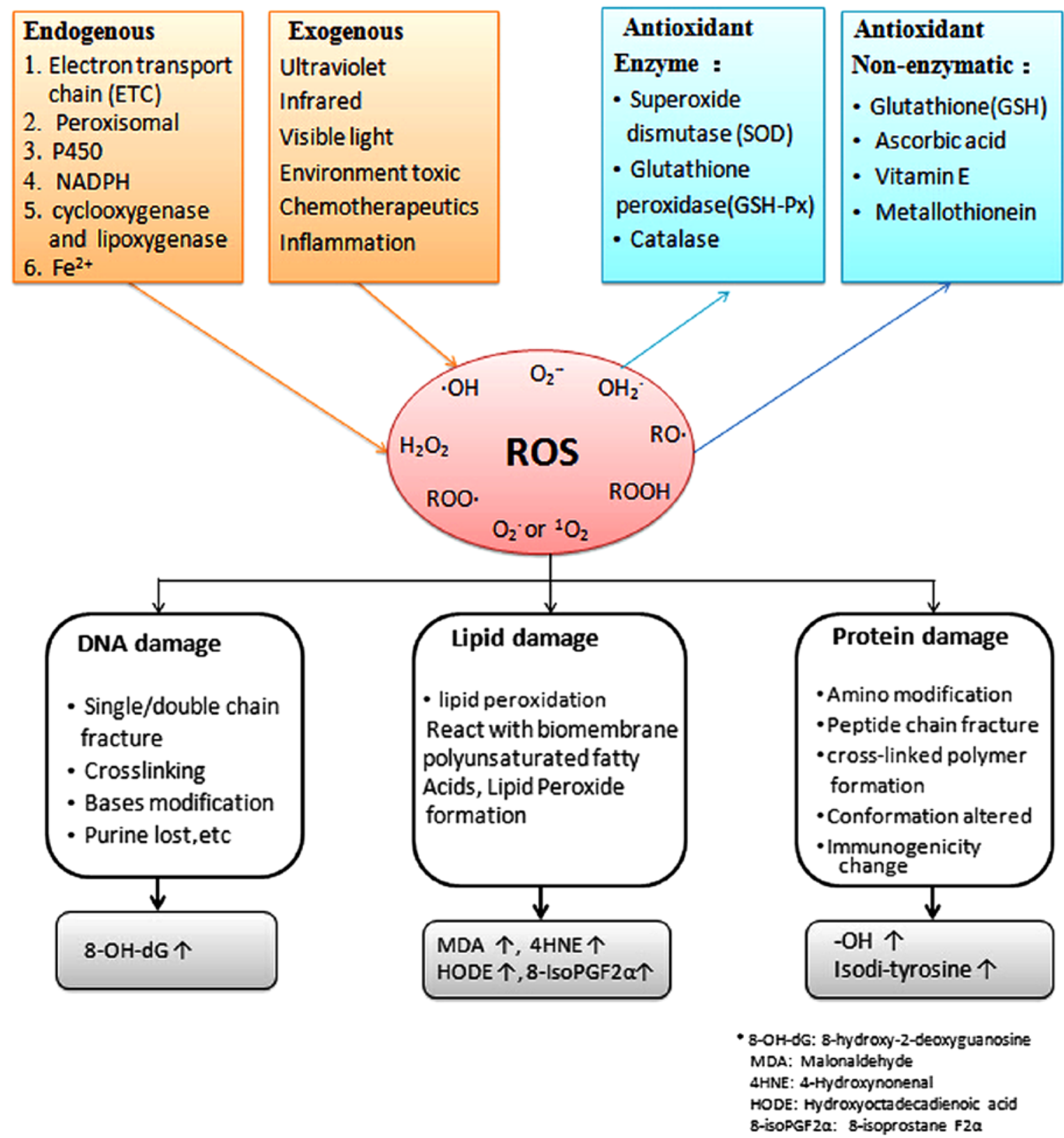

Figure 1. Factors associated with ROS production and cellular damage. ROS, reactive oxygen species.

duction $(42,43)$. Due to or under some external causes, such as illness or aging, the oxidative balance of the body is compromised, leading to pathological changes. ROS damage proteins, lipids, and in particular, DNA molecules (44); these process are associated with the development of cell aging, chronic inflammation, cancer and apoptosis.

$\mathrm{OH}^{*}$ is the most reactive ROS. It can react with different DNA moieties, including purine, pyrimidine and the deoxyribose backbone, resulting in irreversible mutations, such as single and double chain fracture, crosslinking between or within the chain, base modification and purine loss (16). mtDNA is less protected than nuclear DNA (45) and is more sensitive to oxidative stress (46). Superoxide anions mainly damage biological membranes, causing lipid peroxidation that generates cytotoxic secondary products of lipid oxidation. ROS also damage amino acid residues, particularly cysteine and methionine residues, and damage the structure of critical areas, which leads to misfolding or dysfunction (47).

The TM is the most sensitive tissue to oxidative damage in the anterior chamber (48). Oxidative stress to the TM can cause much damage, such as reduce TM mitochondrial respiratory activity, leading to growth arrest (49), affect ECM structure (50) and lead to ECM accumulation (51), damage TM cellular DNA (52), alter membrane permeability (53), cause the rearrangement of TM cell cytoskeletal structures, cause the loss of cell-matrix adhesion (54), affect cell cycle progression (55), cause inflammatory cytokine release $(56,57)$, and trigger apoptosis $(58,59)$, as well as many forms of cell death (60). Cell death may cause a free radical attack $(61,62)$ and the loss or altered functionality of TM cells, leading to even more oxidative stress, thus beginning a vicious cycle (63). At least, ROS alter the morphology, function and drainage of the anterior 


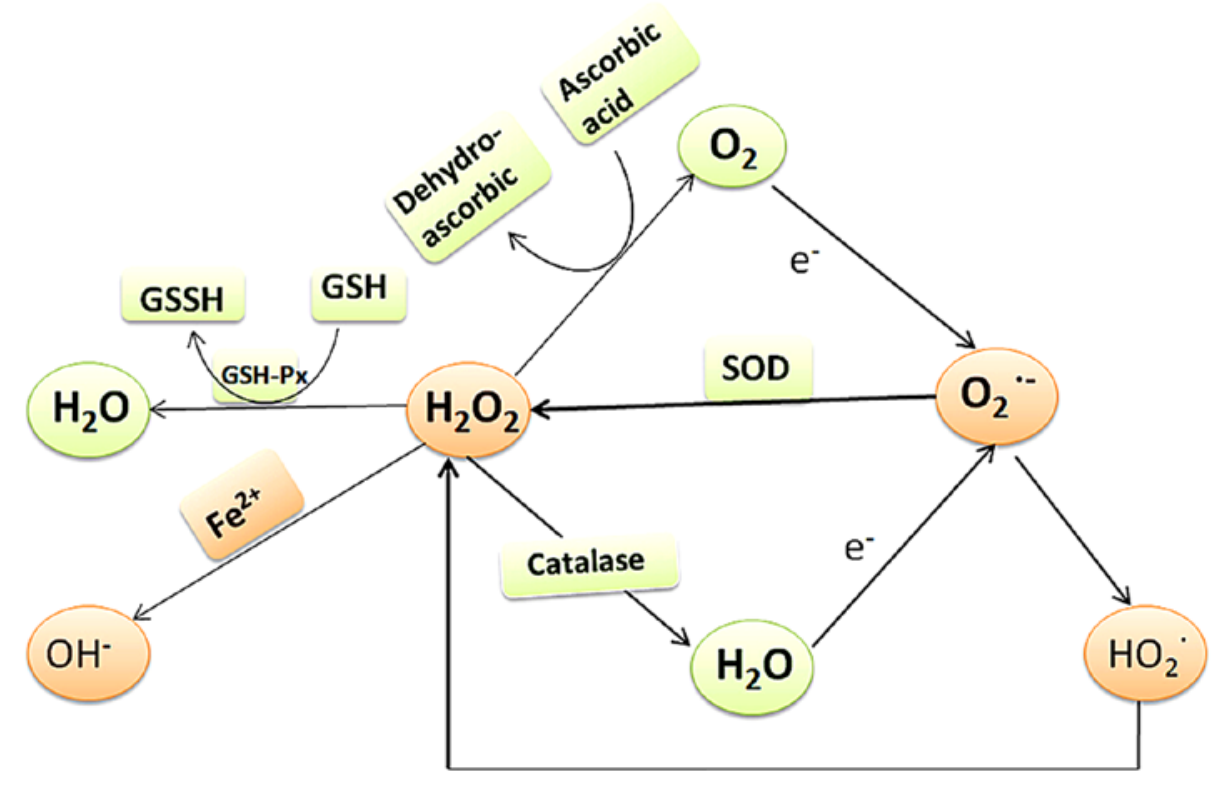

Figure 2. Mechanisms related to antioxidant activity. SOD, superoxide dismutase; GSH-px, glutathione peroxidase.

chamber filter channel that eventually leads to an increase in IOP (40,39,54,63-70). In patients with glaucoma, the levels of mtDNA damage and lipid peroxidation products in the TM are significantly higher compared with the controls $(14,69,71)$ and their visual field defects, due to retinal ganglion cell degeneration, are directly proportional to oxidative damage to the TM (69,70).

\section{Antioxidants in the TM}

The ability of antioxidants in TM cells to counter oxidative damage is critical to their survival.

In a biological system, antioxidants can be categorized as enzymatic or non-enzymatic (Figs. 1 and 2). Antioxidant enzymes in the TM include superoxide dismutase (SOD), glutathione peroxidase (GSH-Px), catalase and glutathione reductase (GSH-Re) (63,72). Non-enzymatic antioxidants include endogenously produced GSH or dietary compounds, such as vitamins $\mathrm{C}$ and $\mathrm{E}$, and certain metal reduction proteins. The function of these molecules is to capture free radicals by accepting the unpaired electron and passing it on. In nocturnal animals, the levels of antioxidants in aqueous humor are much lower than in diurnal animals, suggesting that non-enzymatic antioxidants are consumed to protect the eyes from exogenous light damage (73-75).

In addition to the antioxidants mentioned above, TM cells have been shown to be able to synthesize a specific set of proteins, such as $\beta$-crystalline, that may act as molecular chaperones to prevent oxidative damage (76). Compared with plasma, the concentrations of ascorbic acid $(530 \mu \mathrm{M})$ and $\mathrm{GSH}(5.5 \mu \mathrm{M})$ in aqueous humor are higher, which is important for maintaining the anterior chamber and TM oxidation balance (64). Ascorbic acid is considered to be the main antioxidant in the eye due to its high concentration in many ocular tissues (77-79). In the aqueous humor, the concentration of ascorbic acid is 15 -fold higher than that in plasma (80). The mechanisms responsible for the antioxidant activity of ascorbic acid include the direct absorption of
UV light (81), quenching the fluorescence of biomolecules, and controlling fluorescence-mediated bio-transformations (82). A number of studies have demonstrated that the antioxidant activity of ascorbic acid depends on its concentration; ascorbic acid can also promote oxidation (83-85). Ascorbic acid can cause the decomposition of lipid peroxide and the generation of endogenous genotoxic substances; these substances can damage DNA and the level of these substance increases with the ascorbic acid concentration (86).

Oxidation and antioxidant systems in the eye crossover to maintain balance. Classical examples include the GPX-GSH-GR-NADPH and GSH-vitamin C and E systems. These systems work together so a deficiency in one antioxidant is not always associated with eye pathologies (73). ROS production essentially depends on mitochondrial function and on the levels of antioxidant defenses (87). Age (88-90), diet and gene polymorphisms (91) also affect the ability of the body to resist and protect itself against oxidative damage.

In patients with primary open-angle glaucoma, the levels of circulating GSH are decreased, which indicates that the antioxidant defense system has been compromised (92). The levels of total reactive antioxidant potential and water soluble antioxidants, such as ascorbate and tyrosine in aqueous humor also decrease (93). The level of antioxidant enzymes in the aqueous humor of patients with primary open-angle glaucoma is controversial. Some articles have reported an increase in antioxidant enzymes $(94,95)$, whereas others have reported a decrease $(96,97)$. Whether the content of antioxidant enzymes correlates with the clinical course of primary open-angle glaucoma remains to be elucidated.

\section{TM and oxidative stress in vitro/in vivo}

Establishing a reliable oxidative stress model is essential to elucidating the mechanisms of oxidative stress and the efficacy of antioxidant drugs. In in vitro experiments, $\mathrm{H}_{2} \mathrm{O}_{2}$ is the most widely used agent in oxidative stress models. $\mathrm{H}_{2} \mathrm{O}_{2}$ can easily 
pass through cell membranes and into cells, where it may react with iron ions to produce very active free radicals. In TM cells, the concentration of $\mathrm{H}_{2} \mathrm{O}_{2}$ usually ranges from $100 \mu \mathrm{M}$ to $1 \mathrm{mM}(54,57,98-100)$. Treatment concentrations and times vary significantly among different studies. In some studies, TM cells were exposed to $200 \mu \mathrm{M} \mathrm{H}_{2} \mathrm{O}_{2}$ for $30 \min (57)$ or $300 \mu \mathrm{M}$ for $1 \mathrm{~h}$ (103) which caused a $60 \%$ reduction in mitochondrial activity. In other studies, TM cells were exposed to $1 \mathrm{mM} \mathrm{H}_{2} \mathrm{O}_{2}$ for $24 \mathrm{~h}$, resulting in a rate of cell death of apprximately $50 \%(98,99)$. The difference here may be due to the instability of $\mathrm{H}_{2} \mathrm{O}_{2} \cdot \mathrm{H}_{2} \mathrm{O}_{2}$ is usually stable in solutions with a $\mathrm{pH}$ between 3.5-4.5; however, it easily decomposes in alkaline solutions or when exposed to bright light, particularly shortwave radiation. Tert-butyl hydroperoxide (tBHP) is a common lipid hydroperoxide. Unlike $\mathrm{H}_{2} \mathrm{O}_{2}$, tBHP is not degraded by catalase, which allows it to cause oxidative stress for a longer period of time compared with $\mathrm{H}_{2} \mathrm{O}_{2}(101)$.

In the past, the degree of oxidative stress was usually measured by quantifying the activity of SOD, catalase and GSH-Px (93); however, currently the levels of products of oxidation such as oxidized lipids, proteins, amino acids and DNA are measured as they are more stable. Measured products include the lipid peroxidation products, hydroxyoctadecadienoic acid and malondialdehyde, and the DNA oxidative modification marker, 8-OH deoxyguanosine (Fig. 1) (11).

In TM cells, after exogenous oxidative treatment, the following damage has been observed: a decrease in cellular activity (102), a change in cell cycle progression, the inhibition of cell proliferation (103), and the promotion of cellular senescence (100). Oxidation treatment can rearrange the cell cytoskeleton structure (actin and vimentin) $(54,102)$, increase the synthesis of ECM (fibronectin, plasminogen activator inhibitor 1, connective tissue growth factor) (103), decrease the adhesion to ECM (fibronectin, laminin, collagen types I and IV) (54), and increase the expression of some inflammatory mediators [interleukin (IL)-1 $\alpha$, IL-6, IL-8 and endothelial-leukocyte adhesion molecule 1 (ELAM-1)] (57,103), leading to cell apoptosis and death (100). Nuclear factor (NF) $-\kappa B$ is the most relevant pathway associated with $\mathrm{H}_{2} \mathrm{O}_{2}$-induced changes $(54,103)$. $\mathrm{NF}-\mathrm{kB}$ expression increases, and activate downstream target genes, including mitogen-activated protein kinase (MAPK) signaling pathways; phosphoinositide 3-kinase (PI3K)-Akt, extracellular signal-regulated kinase (ERK) and p38 have all been reported to contribute to cellular damage $(101,102)$.

Oxidative in vivo models are diverse; however, few studies have examined oxidative stress in the TM. Non-specific methods include the use of irradiation, inhaled ozone and hypoxiareperfusion, which may hardly reach effective concentrations in the TM during a short period of time. For the research of oxidative stress in the TM, methods involving the injection of drugs near targeted tissues, which have been widely reported in many other ocular tissues, such as the retina and lens $(104,105)$ may be considered for future studies (106).

\section{Clinical studies on protection against oxidative stress for the treatment of glaucoma}

A series of substances have been reported to have potential antioxidant effects, such as creatine, $\alpha$-lipoic acid, nicotinamide and catechins. These substances mainly include some antioxidant enzymes, oxidase inhibitors, vitamins $\mathrm{C}$ and $\mathrm{E}$, some metal ions such as Se and $\mathrm{Zn}$, and some hormones. Some foods which have ingredients such as as polyphenolic flavonoids (107) such as tea, coffee, dark chocolate (108), red wine (109), anthocyanosides (110) found in blueberries and Ginkgo biloba (111) also have antioxidant effects. However, all of these antioxidant substances lack targeting and specificity. There are some compounds that have been shown to protect TM cells from oxidative stress in vitro $(103,112)$; however, their effects are limited in vitro. In vivo, dorzolamide, a carbonic anhydrase inhibitor, has been reported to reduce oxidative products and increase antioxidant enzyme activity in the aqueous humor of patients with primary open-angle glaucoma (113).

It is worth emphasizing that although oxidative stress has been confirmed to play a role in many diseases, antioxidant supplements are not always good for the health (114) and sometimes may even cause harm (115-117). In a 2-year randomized controlled trial, oral antioxidant supplementation in 117 patients with mild or moderate glaucoma had no effect (118), and some researchers have indicated that antioxidants promote cancer cell metastasis (119). As in studies of other systems, the research of antioxidant treatments for TM protection or glaucoma needs to be designed to elucidate how to use antioxidant compounds, determine when is the best intervention time (to prevent or to treat), and who (healthy or unhealthy individuals) can benefit from these compounds.

\section{Conclusion and future perspectives}

Although many questions remain unanswered, it is becoming increasingly clear that oxidative stress-induced damage to the TM is related to glaucoma, which may inspire futher studies to find better and more stable antioxidants and better models with which to elucidate the mechanisms involved, and to determine whether in vitro findings can translate into in vivo observations. The regulation of the oxidative/redox balance may be the ultimate target for protecting the TM from oxidative stress and preventing glaucoma.

\section{Acknowledgements}

This study was partially supported by the National Natural Science Foundation of China (no. 81271002). We would like to thank Dr He Y.X. and Dr Zhang G.X. for providing inspiration and encouragement.

\section{References}

1. Kingman S: Glaucoma is second leading cause of blindness globally. Bull World Health Organ 82: 887-888, 2004.

2. Bojikian KD, Moore DB, Chen PP and Slabaugh MA: Optic disc hemorrhage after phacoemulsification in patients with glaucoma. ISRN Ophthalmol 2014: 574054, 2014.

3. Kass MA, Heuer DK, Higginbotham EJ, Johnson CA, Keltner JL, Miller JP,Parrish RK II, Wilson MR and Gordon MO: The Ocular Hypertension Treatment Study: A randomized trial determines that topical ocular hypotensive medication delays or prevents the onset of primary open-angle glaucoma. Arch Ophthalmol 120: 701-830, 2002

4. Heijl A, Leske MC, Bengtsson B, Hyman L, Bengtsson B and Hussein M; Early Manifest Glaucoma Trial Group: Reduction of intraocular pressure and glaucoma progression: Results from the Early Manifest Glaucoma Trial. Arch Ophthalmol 120: 1268-1279, 2002.

5. Yue BY: The extracellular matrix and its modulation in the trabecular meshwork. Surv Ophthalmol 40: 379-390, 1996. 
6. Flammer J: The vascular concept of glaucoma. Surv Ophthalmol 38 (Suppl): S3-S6, 1994.

7. Shen F, Chen B, Danias J, Lee KC, Lee H, Su Y, Podos SM and Mittag TW: Glutamate-induced glutamine synthetase expression in retinal Muller cells after short-term ocular hypertension in the rat. Invest Ophthalmol Vis Sci 45: 3107-3112, 2004.

8. Galassi F, Renieri G, Sodi A, Ucci F, Vannozzi L and Masini E: Nitric oxide proxies and ocular perfusion pressure in primary open angle glaucoma. Br J Ophthalmol 88: 757-760, 2004.

9. Chung HS, Harris A, Evans DW, Kagemann L, Garzozi HJ and Martin B: Vascular aspects in the pathophysiology of glaucomatous optic neuropathy. Surv Ophthalmol 43 (Suppl 1): S43-S50, 1999.

10. Lütjen-Drecoll E: Morphological changes in glaucomatous eyes and the role of TGFbeta2 for the pathogenesis of the disease. Exp Eye Res 81: 1-4, 2005.

11. Dalle-Donne I, Rossi R, Colombo R, Giustarini D and Milzani A: Biomarkers of oxidative damage in human disease. Clin Chem 52: 601-623, 2006.

12. Weidinger A and Kozlov AV: Biological activities of reactive oxygen and nitrogen species: Oxidative stress versus signal transduction. Biomolecules 5: 472-484, 2015.

13. Giustarini D, Dalle-Donne I, Tsikas D and Rossi R: Oxidative stress and human diseases: Origin, link, measurement, mechanisms, and biomarkers. Crit Rev Clin Lab Sci 46: 241-281, 2009.

14. Babizhayev MA: Lipid fluorophores of the human crystalline lens with cataract. Graefes Arch Clin Exp Ophthalmol 227: 384-391, 1989.

15. Green K: Free radicals and aging of anterior segment tissues of the eye: A hypothesis. Ophthalmic Res 27 (Suppl 1): 143-149, 1995.

16. Jezek $\mathrm{P}$ and Hlavatá L: Mitochondria in homeostasis of reactive oxygen species in cell, tissues, and organism. Int J Biochem Cell Biol 37: 2478-2503, 2005.

17. Turrens JF: Mitochondrial formation of reactive oxygen species. J Physiol 552: 335-344, 2003

18. Rinnerthaler M, Bischof J, Streubel MK, Trost A and Richter K Oxidative stress in aging human skin. Biomolecules 5: 545-589, 2015.

19. Harman D: The biologic clock: The mitochondria? J Am Geriatr Soc 20: 145-147, 1972

20. Chance B, Sies H and Boveris A: Hydroperoxide metabolism in mammalian organs. Physiol Rev 59: 527-605, 1979.

21. Muller FL, Lustgarten MS, Jang Y, Richardson A and Van Remmen H: Trends in oxidative aging theories. Free Radic Biol Med 43: 477-503, 2007.

22. Fransen M, Nordgren M, Wang B and Apanasets O: Role of peroxisomes in ROS/RNS-metabolism: Implications for human disease. Biochim Biophys Acta 1822: 1363-1373, 2012.

23. Harrison R: Structure and function of xanthine oxidoreductase: Where are we now? Free Radic Biol Med 33: 774-797, 2002

24. Bae YS, Oh H, Rhee SG and Yoo YD: Regulation of reactive oxygen species generation in cell signaling. Mol Cells 32: 491-509, 2011.

25. Gorsky LD, Koop DR and Coon MJ: On the stoichiometry of the oxidase and monooxygenase reactions catalyzed by liver microsomal cytochrome P-450. Products of oxygen reduction. J Biol Chem 259: 6812-6817, 1984.

26. Benham AM, van Lith M, Sitia R and Braakman I: Erol-PDI interactions, the response to redox flux and the implications for disulfide bond formation in the mammalian endoplasmic reticulum. Philos Trans R Soc Lond B Biol Sci 368: 20110403, 2013.

27. Bhandary B, Marahatta A, Kim HR and Chae HJ: An involvement of oxidative stress in endoplasmic reticulum stress and its associated diseases. Int J Mol Sci 14: 434-456, 2012.

28. Rinnerthaler M, Büttner S, Laun P, Heeren G, Felder TK, Klinger H, Weinberger M, Stolze K, Grousl T, Hasek J, et al: Ynolp/Aim14p, a NADPH-oxidase ortholog, controls extramitochondrial reactive oxygen species generation, apoptosis, and actin cable formation in yeast. Proc Natl Acad Sci USA 109: 8658-8663, 2012.

29. Block K, Gorin Y and Abboud HE: Subcellular localization of Nox4 and regulation in diabetes. Proc Natl Acad Sci USA 106: 14385-14390, 2009.

30. Krause KH: Tissue distribution and putative physiological function of NOX family NADPH oxidases. Jpn J Infect Dis 57: S28-S29, 2004.

31. Nauseef WM: Biological roles for the NOX family NADPH oxidases. J Biol Chem 283: 16961-16965, 2008.

32. Kukreja RC, Kontos HA, Hess ML and Ellis EF: PGH synthase and lipoxygenase generate superoxide in the presence of NADH or NADPH. Circ Res 59: 612-619, 1986.
33. Norren DV and Vos JJ: Spectral transmission of the human ocular media. Vision Res 14: 1237-1244, 1974.

34. Spector A: Oxidative stress-induced cataract: Mechanism of action. FASEB J 9: 1173-1182, 1995.

35. Bryszewska M, Piasecka A, Zavodnik LB, Distel L and Schüssler H: Oxidative damage of Chinese hamster fibroblasts induced by t-butyl hydroperoxide and by X-rays. Biochim Biophys Acta 1621: 285-291, 2003.

36. Saccà SC, Pulliero A and Izzotti A: The dysfunction of the trabecular meshwork during glaucoma course. J Cell Physiol 230: 510-525, 2015.

37. Shoham A, Hadziahmetovic M, Dunaief JL, Mydlarski MB and Schipper HM: Oxidative stress in diseases of the human cornea. Free Radic Biol Med 45: 1047-1055, 2008.

38. Alvarado J, Murphy C and Juster R: Trabecular meshwork cellularity in primary open-angle glaucoma and nonglaucomatous normals. Ophthalmology 91: 564-579, 1984.

39. Kahn MG, Giblin FJ and Epstein DL: Glutathione in calf trabecular meshwork and its relation to aqueous humor outflow facility. Invest Ophthalmol Vis Sci 24: 1283-1287, 1983.

40. Wielgus AR and Sarna T: Ascorbate enhances photogeneration of hydrogen peroxide mediated by the iris melanin. Photochem Photobiol 84: 683-691, 2008.

41. Spector A and Garner WH: Hydrogen peroxide and human cataract. Exp Eye Res 33: 673-681, 1981.

42. Sundaresan M, Yu ZX, Ferrans VJ, Irani K and Finkel T: Requirement for generation of $\mathrm{H}_{2} \mathrm{O}_{2}$ for platelet-derived growth factor signal transduction. Science 270: 296-299, 1995.

43. Gulati P, Klöhn PC, Krug H, Göttlicher M, Markova B, Böhmer FD and Herrlich P: Redox regulation in mammalian signal transduction. IUBMB Life 52: 25-28, 2001.

44. Beckman KB and Ames BN: Mitochondrial aging: Open questions. Ann NY Acad Sci 854: 118-127, 1998.

45. Balansky R, Izzotti A, Scatolini L, D'Agostini F and De Flora S: Induction by carcinogens and chemoprevention by $\mathrm{N}$-acetylcysteine of adducts to mitochondrial DNA in rat organs. Cancer Res 56: 1642-1647, 1996.

46. de Grey AD: A proposed refinement of the mitochondrial free radical theory of aging. Bioessays 19: 161-166, 1997.

47. Dean RT, Fu S, Stocker R and Davies MJ: Biochemistry and pathology of radical-mediated protein oxidation. Biochem J 324: $1-18,1997$.

48. Izzotti A, Saccà SC, Longobardi M and Cartiglia C: Sensitivity of ocular anterior chamber tissues to oxidative damage and its relevance to the pathogenesis of glaucoma. Invest Ophthalmol Vis Sci 50: 5251-5258, 2009.

49. Clopton DA and Saltman P: Low-level oxidative stress causes cell-cycle specific arrest in cultured cells. Biochem Biophys Res Commun 210: 189-196, 1995.

50. Knepper PA, Goossens W and Palmberg PF: Glycosaminoglycan stratification of the juxtacanalicular tissue in normal and primary open-angle glaucoma. Invest Ophthalmol Vis Sci 37: 2414-2425, 1996.

51. Knepper PA, Goossens W, Hvizd M and Palmberg PF: Glycosaminoglycans of the human trabecular meshwork in primary open-angle glaucoma. Invest Ophthalmol Vis Sci 37: 1360-1367, 1996.

52. Izzotti A,Longobardi M, Cartiglia C and Saccà SC: Mitochondrial damage in the trabecular meshwork occurs only in primary open-angle glaucoma and in pseudoexfoliative glaucoma. PLoS One 6: e14567, 2011

53. Alvarado JA, Alvarado RG, Yeh RF, Franse-Carman L, Marcellino GR and Brownstein MJ: A new insight into the cellular regulation of aqueous outflow: How trabecular meshwork endothelial cells drive a mechanism that regulates the permeability of Schlemm's canal endothelial cells. Br J Ophthalmol 89: 1500-1505, 2005.

54. Zhou L, Li Y and Yue BY: Oxidative stress affects cytoskeletal structure and cell-matrix interactions in cells from an ocular tissue: The trabecular meshwork. J Cell Physiol 180: 182-189, 1999.

55. Giancotti FG: Integrin signaling: Specificity and control of cell survival and cell cycle progression. Curr Opin Cell Biol 9: 691-700, 1997.

56. Welge-Lüssen U and Birke K: Oxidative stress in the trabecular meshwork of POAG. Klin Monbl Augenheilkd 227: 99-107, 2010 (In German).

57. Li G, Luna C, Liton PB, Navarro I, Epstein DL and Gonzalez P. Sustained stress response after oxidative stress in trabecular meshwork cells. Mol Vis 13: 2282-2288, 2007. 
58. Dröge W: Free radicals in the physiological control of cell function. Physiol Rev 82: 47-95, 2002.

59. Frisch SM and Ruoslahti E: Integrins and anoikis. Curr Opin Cell Biol 9: 701-706, 1997.

60. Martindale JL and Holbrook NJ: Cellular response to oxidative stress: Signaling for suicide and survival. J Cell Physiol 192: $1-15,2002$.

61. Yan DB, Trope GE, Ethier CR, Menon IA and Wakeham A: Effects of hydrogen peroxide-induced oxidative damage on outflow facility and washout in pig eyes. Invest Ophthalmol Vis Sci 32: 2515-2520, 1991.

62. Padgaonkar V, Giblin FJ, Leverenz V, Lin LR and Reddy VN: Studies of $\mathrm{H}_{2} \mathrm{O}_{2}$-induced effects on cultured bovine trabecular meshwork cells. J Glaucoma 3: 123-131, 1994.

63. De La Paz MA and Epstein DL: Effect of age on superoxide dismutase activity of human trabecular meshwork. Invest Ophthalmol Vis Sci 37: 1849-1853, 1996.

64. Alvarado J, Murphy C, Polansky J and Juster R: Age-related changes in trabecular meshwork cellularity. Invest Ophthalmol Vis Sci 21: 714-727, 1981.

65. Freedman SF, Anderson PJ and Epstein DL: Superoxide dismutase and catalase of calf trabecular meshwork. Invest Ophthalmol Vis Sci 26: 1330-1335, 1985.

66. Tan JC, Peters DM and Kaufman PL: Recent developments in understanding the pathophysiology of elevated intraocular pressure. Curr Opin Ophthalmol 17: 168-174, 2006.

67. Gabelt BT and Kaufman PL: Changes in aqueous humor dynamics with age and glaucoma. Prog Retin Eye Res 24: 612-637, 2005.

68. Kumar DM and Agarwal N: Oxidative stress in glaucoma: A burden of evidence. J Glaucoma 16: 334-343, 2007.

69. Izzotti A, Saccà SC, Cartiglia $\mathrm{C}$ and De Flora S: Oxidative deoxyribonucleic acid damage in the eyes of glaucoma patients. Am J Med 114: 638-646, 2003.

70. Saccà SC, Pascotto A, Camicione $\mathrm{P}$, Capris $\mathrm{P}$ and Izzotti $\mathrm{A}$ : Oxidative DNA damage in the human trabecular meshwork: Clinical correlation in patients with primary open-angle glaucoma. Arch Ophthalmol 123: 458-463, 2005.

71. Zanon-Moreno V,Marco-VenturaP,Lleo-Perez A,Pons-VazquezS, Garcia-Medina JJ, Vinuesa-Silva I, Moreno-Nadal MA and Pinazo-Duran MD: Oxidative stress in primary open-angle glaucoma. J Glaucoma 17: 263-268, 2008.

72. Nguyen KP, Chung ML, Anderson PJ, Johnson M and Epstein DL: Hydrogen peroxide removal by the calf aqueous outflow pathway. Invest Ophthalmol Vis Sci 29: 976-981, 1988.

73. Chen Y, Mehta G and Vasiliou V: Antioxidant defenses in the ocular surface. Ocul Surf 7: 176-185, 2009.

74. Behndig A, Svensson B, Marklund SL and Karlsson K: Superoxide dismutase isoenzymes in the human eye. Invest Ophthalmol Vis Sci 39: 471-475, 1998.

75. Reiss GR, Werness PG, Zollman PE and Brubaker RF: Ascorbic acid levels in the aqueous humor of nocturnal and diurnal mammals. Arch Ophthalmol 104: 753-755, 1986.

76. Tamm ER, Russell P, Johnson DH and Piatigorsky J: Human and monkey trabecular meshwork accumulate alpha B-crystallin in response to heat shock and oxidative stress. Invest Ophthalmol Vis Sci 37: 2402-2413, 1996.

77. Hanashima C and Namiki H: Reduced viability of vascular endothelial cells by high concentration of ascorbic acid in vitreous humor. Cell Biol Int 23: 287-298, 1999.

78. Brubaker RF, Bourne WM, Bachman LA and McLaren JW: Ascorbic acid content of human corneal epithelium. Invest Ophthalmol Vis Sci 41: 1681-1683, 2000.

79. Dreyer R and Rose RC: Lacrimal gland uptake and metabolism of ascorbic acid. Proc Soc Exp Biol Med 202: 212-216, 1993.

80. Becker B: Chemical composition of human aqueous humor; effects of acetazoleamide. AMA Arch Opthalmol 57: 793-800, 1957.

81. Giblin FJ, McCready JP, Kodama T and Reddy VN: A direct correlation between the levels of ascorbic acid and $\mathrm{H}_{2} \mathrm{O}_{2}$ in aqueous humor. Exp Eye Res 38: 87-93, 1984.

82. Ringvold A: The significance of ascorbate in the aqueous humour protection against UV-A and UV-B. Exp Eye Res 62: 261-264, 1996.

83. Griffiths HR and Lunec J: Ascorbic acid in the 21st century more than a simple antioxidant. Environ Toxicol Pharmacol 10 173-182, 2001

84. Andorn AC, Britton RS and Bacon BR: Ascorbate-stimulated lipid peroxidation in human brain is dependent on iron but not on hydroxyl radical. J Neurochem 67: 717-722, 1996.

85. Song JH, Shin SH and Ross GM: Oxidative stress induced by ascorbate causes neuronal damage in an in vitro system. Brain Res 895: 66-72, 2001.
86. Lee SH, Oe T and Blair IA: Vitamin C-induced decomposition of lipid hydroperoxides to endogenous genotoxins. Science 292 2083-2086, 2001.

87. Camougrand $\mathrm{N}$ and Rigoulet $\mathrm{M}$ : Aging and oxidative stress: Studies of some genes involved both in aging and in response to oxidative stress. Respir Physiol 128: 393-401, 2001.

88. Cejková J, Vejrazka M, Pláteník J and Stípek S: Age-related changes in superoxide dismutase, glutathione peroxidase, catalase and xanthine oxidoreductase/xanthine oxidase activities in the rabbit cornea. Exp Gerontol 39: 1537-1543, 2004

89. Samiec PS, Drews-Botsch C, Flagg EW, Kurtz JC, Sternberg P Jr, Reed RL and Jones DP: Glutathione in human plasma: Decline in association with aging, age-related macular degeneration, and diabetes. Free Radic Biol Med 24: 699-704, 1998.

90. Serbecic N and Beutelspacher SC: Vitamins inhibit oxidantinduced apoptosis of corneal endothelial cells. Jpn J Ophthalmol 49: 355-362, 2005.

91. Wallace DC: A mitochondrial paradigm of metabolic and degenerative diseases, aging, and cancer: A dawn for evolutionary medicine. Annu Rev Genet 39: 359-407, 2005.

92. Gherghel D, Griffiths HR, Hilton EJ, Cunliffe IA and Hosking SL: Systemic reduction in glutathione levels occurs in patients with primary open-angle glaucoma. Invest Ophthalmol Vis Sci 46: 877-883, 2005.

93. Ferreira SM, Lerner SF, Brunzini R, Evelson PA and Llesuy SF: Oxidative stress markers in aqueous humor of glaucoma patients. Am J Ophthalmol 137: 62-69, 2004.

94. Ghanem AA, Arafa LF and El-Baz A: Oxidative stress markers in patients with primary open-angle glaucoma. Curr Eye Res 35: 295-301, 2010

95. Yang J, Tezel G, Patil RV, Romano C and Wax MB: Serum autoantibody against glutathione S-transferase in patients with glaucoma. Invest Ophthalmol Vis Sci 42: 1273-1276, 2001.

96. Bagnis A, Izzotti A, Centofanti M and Saccà SC: Aqueous humor oxidative stress proteomic levels in primary open angle glaucoma. Exp Eye Res 103: 55-62, 2012.

97. Majsterek I, Malinowska K, Stanczyk M, Kowalski M, Blaszczyk J, Kurowska AK, Kaminska A, Szaflik J and Szaflik JP: Evaluation of oxidative stress markers in pathogenesis of primary open-angle glaucoma. Exp Mol Pathol 90: 231-237, 2011.

98. Famili A, Ammar DA and Kahook MY: Ethyl pyruvate treatment mitigates oxidative stress damage in cultured trabecular meshwork cells. Mol Vis 19: 1304-1309, 2013.

99. Ammar DA, Hamweyah KM and Kahook MY: Antioxidants protect trabecular meshwork cells from hydrogen peroxideinduced cell death. Transl Vis Sci Technol 1: 4, 2012.

100. Yu AL, Fuchshofer R, Kampik A and Welge-Lüssen U: Effects of oxidative stress in trabecular meshwork cells are reduced by prostaglandin analogues. Invest Ophthalmol Vis Sci 49: 4872-4880, 2008

101. Yang Y, Liu X, Huang J, Zhong Y, Mao Z, Xiao H, Li M and Zhuo Y: Inhibition of p38 mitogen-activated protein kinase phosphorylation decrease tert-butyl hydroperoxide-induced apoptosis in human trabecular meshwork cells. Mol Vis 18: 2127-2136, 2012.

102. Awai-Kasaoka N, Inoue $\mathrm{T}$, Kameda $\mathrm{T}$, Fujimoto $\mathrm{T}$, Inoue-Mochita $\mathrm{M}$ and Tanihara $\mathrm{H}$ : Oxidative stress response signaling pathways in trabecular meshwork cells and their effects on cell viability. Mol Vis 19: 1332-1340, 2013.

103. Tourtas T, Birke MT, Kruse FE, Welge-Lüssen UC and Birke K: Preventive effects of omega-3 and omega- 6 fatty acids on peroxide mediated oxidative stress responses in primary human trabecular meshwork cells. PLoS One 7: e31340, 2012.

104. Ham WT Jr, Mueller HA, Ruffolo JJ Jr, Millen JE, Cleary SF, Guerry RK and Guerry D III: Basic mechanisms underlying the production of photochemical lesions in the mammalian retina. Curr Eye Res 3: 165-174, 1984.

105. Yokoyama Y, Maruyama K, Yamamoto K, Omodaka K, Yasuda M, Himori N, Ryu M, Nishiguchi KM and Nakazawa T: The role of calpain in an in vivo model of oxidative stressinduced retinal ganglion cell damage. Biochem Biophys Res Commun 451: 510-515, 2014

106. Liu Q, Wu K, Qiu X, Yang Y, Lin X and Yu M: siRNA silencing of gene expression in trabecular meshwork: RhoA siRNA reduces IOP in mice. Curr Mol Med 12: 1015-1027, 2012.

107. Romagnolo DF and Selmin OI: Flavonoids and cancer prevention: A review of the evidence. J Nutr Gerontol Geriatr 31: 206-238, 2012. 
108. Miller KB, Stuart DA, Smith NL, Lee CY, McHale NL, Flanagan JA, Ou B and Hurst WJ: Antioxidant activity and polyphenol and procyanidin contents of selected commercially available cocoa-containing and chocolate products in the United States. J Agric Food Chem 54: 4062-4068, 2006.

109. Haufschild T, Kaiser HJ, Preisig T, Pruente C and Flammer J: Influence of red wine on visual function and endothelin-1 plasma level in a patient with optic neuritis. Ann Neurol 53: 825-826, 2003.

110. Määttä-Riihinen KR, Kähkönen MP, Törrönen AR and Heinonen IM: Catechins and procyanidins in berries of vaccinium species and their antioxidant activity. J Agric Food Chem 53: 8485-8491, 2005.

111. Cybulska-Heinrich A, Mozaffarieh M and Flammer J: Value of non-IOP lowering therapy for glaucoma. Klin Monbl Augenheilkd 230: 114-119, 2013 (In German).

112. Luna C, Li G, Liton PB, Qiu J, Epstein DL, Challa P and Gonzalez P: Resveratrol prevents the expression of glaucoma markers induced by chronic oxidative stress in trabecular meshwork cells. Food Chem Toxicol 47: 198-204, 2009.

113. Zanon-Moreno V, Garcia-Medina JJ, Gallego-Pinazo R, Vinuesa-Silva I, Moreno-Nadal MA and Pinazo-Duran MD: Antioxidant status modifications by topical administration of dorzolamide in primary open-angle glaucoma. Eur J Ophthalmol 19: $565-571,2009$
114. Gutteridge JM and Halliwell B: Antioxidants: Molecules, medicines, and myths. Biochem Biophys Res Commun 393: 561-564, 2010

115. Bjelakovic G, Nikolova D, Simonetti RG and Gluud C: Antioxidant supplements for prevention of gastrointestinal cancers: A systematic review and meta-analysis. Lancet 364: 1219-1228, 2004.

116. Talaulikar VS and Manyonda IT: Vitamin $\mathrm{C}$ as an antioxidant supplement in women's health: A myth in need of urgent burial. Eur J Obstet Gynecol Reprod Biol 157: 10-13, 2011.

117. Kaisar MA and Cucullo L: OTC antioxidant products for the treatment of cardiovascular and other disorders: Popular myth or fact? J Pharmacovigil 3: e136, 2015.

118. Garcia-Medina JJ, Garcia-Medina M, Garrido-Fernandez P, Galvan-Espinosa J, Garcia-Maturana C, Zanon-Moreno V and Pinazo-Duran MD: A two-year follow-up of oral antioxidant supplementation in primary open-angle glaucoma: An openlabel, randomized, controlled trial. Acta Ophthalmol 93: 546-554, 2015

119. Piskounova E, Agathocleous M, Murphy MM, Hu Z, Huddlestun SE,Zhao Z,Leitch AM,Johnson TM, DeBerardinis RJ and Morrison SJ: Oxidative stress inhibits distant metastasis by human melanoma cells. Nature 527: 186-191, 2015. 